\title{
ROMULANOS E KLINGONS EM STAR TREK: ANTAGONISTAS DA GUERRA FRIA OU FUTUROS INTEGRANTES DA ORDEM PACÍFICA?
}

\author{
Dilma Beatriz Rocha Juliano* \\ Jean Raphael Zimmermann Houllou**
}

\begin{abstract}
Resumo: $O$ artigo propõe o estudo de Star Trek: a série original, em específico, em que aparecem, na relação entre a Enterprise e seus inimigos, os Romulanos e os Klingons, na primeira temporada. O seriado sugere a defesa de valores e um modo de operar a política que se coadunam com o funcionamento da "ordem imperial" que surgia no seu contexto de produção, a Guerra Fria. Além disso, também é possível constatar na ficção a presença de desejos da "multidão", já que a ordem imperial pode ser parcialmente entendida como uma reposta aos seus anseios transformadores. As concepções de "Império" e "Multidão" apoiam-se no pensamento de Antonio Negri e Michael Hardt.
\end{abstract}

Palavras Chave: Império. Star Trek. Multidão. Seriado.

Hardt e Negri (2000) situam o início da constituição da ordem imperial no período que engloba as duas Guerras Mundiais, quando várias organizações internacionais produtoras de normas foram construídas, como a Organização das Nações Unidas, Fundo Monetário Internacional, Banco Mundial e organizações humanitárias. Posteriormente, a partir da segunda metade do século XX, corporações industriais e financeiras transnacionais começaram a se estruturar globalmente e a utilizar os Estados-nação como instrumentos para organização do fluxo de capital e pessoas. A união entre o poder político e o econômico em escala global possibilitou o surgimento de ordem chamada de Império pelos autores.

A ordem imperialista anterior ao Império gerava conflitos armados entre os Estados-nação. Nessas guerras, as massas dos diferentes países, que poderiam ter o objetivo comum de lutar contra a exploração do capital, eram levadas a batalhar como inimigas. Benjamin (1987) diagnosticava como o fascismo desviava as massas da revolução ao levá-las para a guerra. Por isso, várias lutas contra a exploração do capital também se colocavam contra elementos do imperialismo, como o nacionalismo e o colonialismo. O Império trouxe uma ordem que se posiciona acima desses conflitos nacionalistas. "Pode-se dizer que a construção do Império e de suas redes globais é uma resposta às diversas lutas contra as modernas máquinas de poder, e especificamente à luta de classes, ditada pelo desejo de libertação da multidão.” (HARDT; NEGRI, 2000). Decorre disso que algumas transformações realizadas pelo Império podem ser

\footnotetext{
* Doutora em Literatura Brasileira e Teoria Literária pela Universidade Federal de Santa Catarina (UFSC). Professora no Programa de Pós-Graduação em Ciências da Linguagem da Universidade do Sul de Santa Catarina (UNISUL). E-mail: dbjuliano@hotmail.com.

** Doutorando em Ciências da Linguagem pela Universidade do Sul de Santa Catarina (UNISUL). Professor no Instituto Federal de Santa Catarina (IFSC). E-mail: jean.raphael@ifsc.edu.br.
} 
entendidas como exigências da multidão ${ }^{1}$. Obviamente que se trata de uma resposta perversa, pois o Império mantém a exploração do trabalho e a propriedade privada.

Contudo, é uma mudança que aponta para as lutas da multidão. É sobre o pressuposto dessa luta que desejamos estudar o seriado Star Trek. Atualmente, com as características do Império bem estabelecidas, principalmente no dito Ocidente, é possível compreender mais claramente como o seriado compartilhava um sensível ${ }^{2}$ com suas transformações na ordem global. Se a série em questão vem ao encontro de um desejo revolucionário da multidão, não podemos enxergá-la simplesmente como, nas palavras de Benjamin (1987, p.224), “despojos atribuídos aos vencedores”, mas como testemunha das tensões que questionam a vitória da ordem dominante.

Slotkin (1998) afirma que na década de 60 os tumultos de Newark e Detroit ${ }^{3}$, causados por várias reivindicações de cunho social, e a Ofensiva $\mathrm{Tet}^{4}$ na Guerra do Vietnã significaram uma crise política e ideológica que abalou o consenso político estadunidense. Hardt e Negri (2000) explicam sobre esse momento que os Estados Unidos iniciam um processo no qual vão abandonando sua tendência imperialista, utilizada até então na Guerra Fria, e assumindo uma atividade de polícia sob a égide da ordem imperial, a qual propunha a superação dos conflitos internacionais entre Estadosnação.

O seriado Star Trek foi transmitido durante a virada da política externa americana descrita acima. Sua estréia se deu em oito de setembro de 1966 e seu último episódio foi ao ar em três de junho de 1969. A série foi criada por Gene Roddenberry, produzida pela Desilu Productions e exibida pela NBC.

Roddenberry criou para sua nave estelar uma tripulação multirracial que trabalhava de maneira harmônica, o que dava a entender que era possível superar as lutas nacionalistas. O criador descreve da seguinte forma a tripulação da Enterprise num guia escrito para orientar os roteiristas: "International in origin, completely multi-racial.

\footnotetext{
${ }^{1}$ O conceito de multidão é de autoria do renascentista Baruch de Espinosa (1983), em sua obra Tratado Político, e é relido por Paolo Virno (2002), na obra A Gramática da Multidão. A multidão, para Virno (2002), se diferencia da concepção de povo por se apresentar como uma pluralidade que permanece como tal na cena pública sem negar o caráter individual dos que a compõem. Para Hardt e Negri (2000), a multidão aparece como uma força social capaz de minar as estruturas da ordem imperial contemporânea.

2 Jacques Rancière afirma, em sua obra A Partilha do Sensivel, que existe na base da política e das formas artísticas uma estética que determina, a priori, o que se dá a sentir: "As artes nunca emprestam às manobras de dominação ou emancipação mais do que lhes podem emprestar, ou seja, muito simplesmente, o que têm em comum com elas: posições e movimentos dos corpos, funções da palavra, repartições do visível e do invisível. E a autonomia de que podem gozar ou a subversão que podem se atribuir repousam sobre a mesma base.” (RANCIÈRE, 2005, p. 26)

${ }^{3}$ Os distúrbios de Newark e Detroit foram o ponto alto de uma série de revoltas urbanas que marcaram a década de 1960. As revoltas eram pautadas em variadas causas, como a violência policial, a pobreza e a falta de representação política.

${ }^{4}$ Foi um ataque realizado pelos norte-vietnamitas contra as forças americanas que resultou num grande impacto na opinião pública norte-americana no sentido da retirada do país do conflito.
} 
But even in this future century we will see some traditional trappings, ornaments, and styles that suggest the Asiatic, the Arabic, the Latin etc. ${ }^{5 ، ~(R O D D E N B E R R Y, ~ 1967, ~ p . ~ 7) . ~}$

Rick Worland (1988) trabalha em seu artigo Captain Kirk: Cold Warrior com a ideia de que no contexto da Guerra Fria os inimigos da nave Enterprise, os Romulanos e os Klingons, simbolizam nações comunistas, respectivamente os chineses e os soviéticos:

Like the Soviet Union with regard to the United States, the Klingon Empire is a vast system roughly equivalent in power and influence to the Federation. Like China in the two decades following the communist revolution, the Romulons are a secondary but nonetheless formidable regional power. Its progressive humanism aside, Star Trek neatly duplicated the configuration of the international Cold War politics of the $1960 \mathrm{~s}^{6}$ (WORLAND, 1988, p.109-117, grifos nossos).

Concordamos apenas em parte com a analogia realizada por Rick Worland. Nosso trabalho visa compreender a relação da Enterprise com seus inimigos considerando exatamente aquilo que na própria citação anterior o autor afirma deixar de lado: o humanismo progressivo. A partir da descrição do Império teorizada por Hardt e Negri (2000), é possível incluir tal questão na associação do seriado com seu contexto de produção. Para nós, esse humanismo progressivo deve ser entendido como um conjunto de valores colocados como universais e compartilhados pela ordem imperial com o intuito de finalizar com as lutas imperialistas entre os Estados-nação.

A primeira aparição dos Romulanos no seriado é dada no episódio Balance of Terror (Temporada 01 Episódio 14) ${ }^{7}$. Os oficiais da ponte de comando avisam o Capitão Kirk que um posto de patrulha terráqueo estava sendo atacado. O posto ficava situado numa zona neutra estabelecida num acordo fechado há mais de um século ao final da guerra entre Terráqueos e Romulanos.

Spock, o primeiro oficial, avisa aos tripulantes da nave que no conflito anterior, tanto os terráqueos quanto os Romulanos contavam com armas atômicas e naves espaciais primitivas que não permitiam a captura nem comunicação visual com o inimigo. Dessa forma, os terráqueos pensam que os Romulanos são belicosos, cruéis e traiçoeiros. Além disso, não é possível saber o que os Romulanos pensam sobre os terráqueos. Por fim, Spock explica que pelo tratado a violação da zona neutra constituiria um ato de guerra.

Nesse momento, o Capitão Kirk toma a palavra e avisa que sobre esse assunto as suas ordens serão precisas e invioláveis. Avisa que nenhum ato ou provocação será considerado razão sensata para entrar na zona neutra. Explica que a Enterprise pode se

\footnotetext{
${ }^{5}$ Nossa tradução: De origem internacional, completamente multi-racial. Mas, mesmo neste século futuro, vamos ver alguns ornamentos, acessórios e estilos tradicionais que sugerem o asiático, o árabe, o latino, etc.

${ }^{6}$ Nossa tradução: Como a União Soviética, no que diz respeito aos Estados Unidos, o Império Klingon é um vasto sistema mais ou menos equivalente em poder e influência para a Federação. Como a China nas duas décadas seguintes à revolução comunista, os Romulons são uma potência regional secundária, mas ainda assim formidável. Deixado de lado o seu humanismo progressivo, Star Trek sistematicamente duplica a configuração das políticas internacionais da Guerra Fria dos anos 1960 (grifos nossos).

${ }^{7}$ Nas próximas referências aos episódios iremos abreviar da seguinte maneira: (T 01 E 14).
} 
defender, mas somente se necessário. Por fim, expõe que para evitar uma guerra espacial tanto a Enterprise como qualquer posto é passível de destruição.

Ao final dessas palavras, o oficial Stiles questiona Kirk se não seria mais correto interceptar e destruir a nave Romulana. Kirk pergunta se o oficial sabe identificar uma nave inimiga após cem anos do último combate. Stiles afirma que como seus antepassados lutaram nessa guerra, ele sabe que os Romulanos constroem naves parecidas com aves de rapina. Kirk responde que essa guerra era a dos antepassados de Stiles e não da humanidade atual.

Nesse trecho, podemos observar a divisão binária da história a partir da constituição do Império, o qual se coloca como uma ordem pacífica eterna que deve abranger a totalidade do espaço (HARDT; NEGRI, 2000). A guerra de cem anos atrás era a guerra do imperialismo, a qual denotava o inimigo como um Outro que deveria ser dominado. Dessa forma, Spock afirma que pela falta de comunicação na guerra anterior os terráqueos rotulam os Romulanos com várias características negativas. Stiles, por sua vez, a exemplo de seus antepassados, quer partir para a perseguição da nave inimiga ignorando a manutenção da paz.

Kirk, ao contrário, apresenta em sua fala a nova guerra do Império. A Enterprise deve agir exclusivamente para manter a paz. O uso da força, por sua vez, é justificado pela concepção de estado de exceção, o qual pressupõe uma ameaça à ordem pacífica. Segundo Hardt e Negri (2000, p. 36- 57), o Império faz uso da força baseado numa ação policial e num estado de exceção permanente:

\begin{abstract}
O que está por trás dessa intervenção não é um permanente estado de emergência e exceção, um permanente estado de emergência e exceção justificado pelo apelo universal a valores essenciais de justiça. [...] As intervenções são sempre excepcionais, apesar de correrem continuadamente; elas tomam forma de ações policiais, porque são voltadas para a manutenção de uma ordem interna. Dessa forma, a intervenção é um mecanismo eficaz que mediante ações policiais contribui diretamente para a construção da ordem moral, normativa e institucional do Império.
\end{abstract}

Após os Romulanos destruírem mais um posto terráqueo, a Enterprise consegue interceptar imagens de dentro da nave inimiga. Os tripulantes descobrem que os Romulanos têm o mesmo aspecto físico, orelhas cumpridas, da raça de Spock, os Vulcanos. Stiles acusa veladamente Spock de ser um traidor. Nese momento, Kirk puxa a cadeira de Stiles e, falando proximamente, afirma que ele deve guardar suas intolerâncias para si, pois a Enterprise não é o lugar para elas. Rick Worland (1988), em razão dessa cena, escreve que Balance of Terror tem um importante subenredo contrário ao racismo. O autor associa a situação de Spock a orientais, principalmente japoneses, que não deveriam ser identificados à China Comunista.

Para nós, esse trecho deve ser associado ao funcionamento do Império, que por meio de seu alargamento, para fins econômicos, propõe a quebra dos binarismos: Eu e o Outro, o branco e o negro, o do dentro e o de fora. Segundo Hardt e Negri (2000), o mercado mundial foi libertado das divisões binárias modernas com o declínio das fronteiras nacionais, fazendo surgir um novo espaço livre de trocas econômicas. As 
antigas diferenças são derrubadas e as pessoas arregimentadas em redes globais de poder, como, por exemplo, as organizações produtivas:

Pessoas de todas as raças, de ambos os sexos e de todas as orientações sexuais devem, potencialmente ser incluídas na corporação; a rotina diária de trabalho precisa ser rejuvenescida com mudanças inesperadas e uma atmosfera de diversão. Derrubem-se as velhas fronteiras e deixem-se umas centenas de flores vicejarem. (HARDT; NEGRI, 2000, p. 209).

Dessa forma, quando o capitão da Enterprise não admite que seu oficial tenha uma atitude de preconceito contra Spock a partir de um raciocínio biológico binário, nós terráqueos e os outros de "orelhas cumpridas", coloca a tripulação de sua nave em consonância com as organizações imperiais que abolem tal maneira de observar o mundo. Lembramos que a exigência de acabar com os nacionalismos e colonialismos partiu da multidão.

Hardt e Negri (2000) também afirmam que embora as diferenças baseadas em binarismos e essencialíssimos biológicos sejam abolidas, na passagem para o Império surgem outras maneiras de marcar hierarquias: através de fatores sociais e culturais. "De acordo com a teoria imperial, portanto, a supremacia e a subordinação raciais não são uma questão teórica, mas surgem da livre competição, uma espécie de mercado meritocrático da cultura." (HARDT; NEGRI, 2000, p. 211).

Esse aspecto pode ser observado no desenrolar do episódio. Spock infere que os Romulanos são descendentes dos Vulcanos que permaneceram numa antiga filosofia de colonização agressiva. A partir disso, sugere que para evitar uma guerra contra esse povo será necessário não demonstrar fraqueza e, portanto, atacar a nave deles. Obviamente que essa filosofia de colonização agressiva pode ser associada à permanecia dos Romulanos na antiga ordem imperialista. Tal constatação é corroborada pelo fato dos Romulanos usarem nomes latinos e se vestiram de maneira similar aos legionários de Roma Antiga. Dessa forma, embora Vulcanos e Romulanos tenham a mesma constituição genética, são desiguais em sua evolução cultural, os primeiros já aderiram à ordem imperial pacífica, ao contrário dos segundos. No entanto, em consonância com a quebra de binarismos e a tendência expansiva do Império, veremos que ao final do episódio, o seriado sugere que os Romulanos, no futuro, irão se integrar à ordem pacífica à qual pertence a Enterprise.

Kirk segue o conselho de Spock e faz uma batalha para prevenir uma guerra de acordo com a ideia de manutenção da paz imperial. Ao final, quando a nave Romulana já está com severas avarias e imobilizada, seu comandante nega a rendição e afirma lamentar ter conhecido Kirk dessa maneira, pois em outra realidade poderia ter se tornado seu amigo. Kirk pergunta qual o propósito de morrer. O comandante afirma que eles são criaturas com deveres e que morrer seria apenas mais um dever a seguir. Para nós, a opção pela morte é uma maneira de ressaltar a guerra imperialista na qual ainda permaneciam os Romulanos e distingui-los dos oficias da Enterprise já inseridos numa nova ordem pacífica do Império. A possibilidade levantada pelo comandante sobre a amizade entre ele e Kirk metaforiza a esperança de que um dia os Romulanos possam, evoluindo culturalmente, se inserir voluntariamente na ordem pacífica. Esse aspecto se 
associa ao Império pela sua ausência de fronteiras e o consequente abarcamento da totalidade do espaço, além de sua apresentação se colocar fora de um regime histórico nascido da conquista, mas sim como uma organização que suspende a história e se localiza no seu fim (HARDT; NEGRI, 2000). Os Romulanos, em razão de sua evolução, serão parceiros dos terráqueos no futuro.

Além disso, em alguns outros episódios, como aquele que apresenta pela primeira vez os Klingons no seriado, Errand of Mercy (T 01 E 26), a própria Enterprise é reposicionada quanto à sua chegada a uma ordem pacífica.

Segundo Rick Worland (1988), as batalhas entre os Klingons e a Federação seriam metáforas para o seriado abordar os conflitos entre a Otan e os seus adversários. "In short, the Klingons and the Federation were firmly established as two ideologically opposed superpower blocs that compete for the hearts and minds of Third World planets." (WORLAND, 1988, p. 109-117). Embora não discordemos que Star Trek estivesse utilizando alguns de seus episódios para tratar da Guerra Fria, acreditamos que além de representar as potências militares daquele momento, o seriado propunha uma nova organização mundial que respondesse às exigências da multidão.

O próprio Worland indica uma associação da Federação dos Planetas Unidos a valores, mais do que a uma organização politicamente instituída, quando, ao recusar uma comparação dela à ONU, entende que a Federação seria mais semelhante a uma concepção de mundo livre. Embora, em seguida, tente associar a Frota Estelar às instituições formais atuantes no período: "The Federation was not, therefore, an outer space United Nations, after all, the Soviet Union, Cuba, Libya, and other American adversaries are U.N. members - but was more akin to the Cold War conception of "the Free World," with Starfleet as Its NATO." (WORLAND, 1988, p. 110).

Worland associa tão diretamente a Frota Estrelar à OTAN porque desconsidera a ordem imperial que o seriado também apresenta. Para nós, as associações entre os organismos políticos formalmente constituídos na década de 60 e o seriado permanecem sempre incompletas se a nova ordem mundial proposta por ele não é considerada.

Na maior parte dos episódios, a Federação e sua Frota Estelar não representam os Estados Unidos e seus aliados na OTAM, mas uma ordem universal, pacífica e democrática a qual associamos ao Império. Apenas por vezes, tais organismos podem ser associados como os Estados Unidos na Guerra Fria, ocasiões nas quais eles são corrigidos por se desviarem da ordem pacífica. Worland descreve como contraditórias as perguntas que coloca ao final de seu artigo:

But it is precisely at this juncture that Star Trek's appeal becomes contradictory: Does the series stir a progressive desire to look ahead and unite disparate people to solve our problems for a brighter future, or is it simply reactionary nostalgia for the continuing desire

\footnotetext{
${ }^{8}$ Nossa tradução: Em suma, os Klingons e a Federação foram firmemente estabelecidos como dois blocos de superpotências ideologicamente opostas que competem pelos corações e mentes dos planetas do Terceiro Mundo.

${ }^{9}$ Nossa tradução: A Federação não foi, portanto, uma Organização das Nações Unidas espacial -, até porque, a União Soviética, Cuba, Líbia e outros adversários americanos são membros da ONU -, mas era mais parecida com a concepção de "Mundo Livre" da Guerra Fria com a Frota Estelar como sua OTAN.
} 
to mold or force the world into patterns suitable only to Americans? ${ }^{10}$ (WORLAND, 1988, p. 117).

Analisemos a aparição dos Klingons em Errand of Mercy para desfazer a contradição apontada por Worland. O primeiro diálogo do seriado apresenta Kirk e Spock lendo uma mensagem lamentosa sobre os insucessos da negociação entre a Federação e o Império Klingon. A mensagem também afirma que a Enterprise deve prosseguir até o primitivo planeta de Organia, pois há desconfianças de que ele seja dominado pelos opositores.

Kirk comenta com Spock que eles não queriam a guerra, mas mesmo assim ela acabou acontecendo. Spock reflete como os humanos várias vezes conseguem aquilo que eles não querem. Nesse trecho, a ordem pacífica que parecia ser uma conquista histórica da Enterprise nos episódios anteriores parece se tornar abalada, como se o seriado voltasse para trás e apresentasse a paz como algo ainda a ser conquistado. Nesse caso, a suspensão e o fim da história afirmadas pelo Império ainda não teriam sido conquistados pela nave. Ao fazer esse movimento, o seriado se torna apto para metaforizar o problema da Guerra Fria sem abdicar do valor universal da paz. O fato de Spock, um extraterrestre, fazer o comentário final reforça a universalidade de tal valor e a importância de sua busca pela humanidade. Ao final do episódio, veremos que a narrativa afirma ainda mais categoricamente tais concepções.

Em Organia, Kirk tenta convencer os habitantes da importância de eles aderirem à Federação para serem protegidos da invasão Klingon. Contudo, os Organianos se negam a proceder dessa forma. Kirk avisa os líderes do planeta sobre a diferença entre o modo de procedimento da Federação e do Império Klingon:

\begin{abstract}
With the Federation, you have a choice. You have none with the Klingons. The Klingons are a military dictatorship. War is their way of life. Life under the Klingon rule would be very unpleasant. We offer you protection. ${ }^{11}$
\end{abstract}

Na sequência, os organianos continuam se negando a aceitar a ajuda da Federação e os Klingons iniciam sua invasão. Kirk ordena que a Enterprise busque reforços. Ele e Spock iniciam sozinhos, dentro do planeta, atitudes de resistência. Dessa forma, explodem um depósito de armas e munições Klingon. Os líderes organianos lamentam a destruição provocada. Kirk compara os organianos a carneiros, acusa-os de não terem coragem de se defender. O capitão começa a ser tomado pelo desejo de guerrear e resistir aos inimigos. Os organianos apenas pedem para que ele não destrua mais nada.

Os Klingons descobrem a presença de Kirk e Spock no planeta, os prendem e afirmam que irão matá-los. Kirk responde que não tem medo, mas que não quer morrer

\footnotetext{
${ }^{10}$ Nossa tradução: Mas é precisamente neste momento que o apelo de Star Trek se torna contraditório: Será que a serie cria o desejo progressivo de olhar em frente e unir pessoas diferentes para resolver os nossos problemas em direção a um futuro melhor, ou é simplesmente a nostalgia reacionária do desejo contínuo de moldar ou forçar o mundo em padrões adequados apenas para os americanos?

${ }^{11}$ Nossa tradução: Com a Federação, vocês têm uma escolha. Você não tem nenhuma com os Klingons. Os Klingons são uma ditadura militar. A guerra é o seu modo de vida. A vida sob o governo Klingon seria muito desagradável. Nós oferecemos proteção.
} 
por pessoas como os organianos, aqueles que não querem lutar. Tal fala demonstra como o Capitão Kirk acaba se deixando tentar pelo desejo de guerra.

Kirk e Spock conseguem fugir da prisão e vão atrás do comandante Klingon, Kor. No momento em que eles iam entrar em luta armada, os organianos revelam-se. Eles são seres tão evoluídos que não possuem mais corpos e não toleram qualquer espécie de violência. Os organianos desarmam todos no planeta e neutralizam as naves de ambas as frotas para impedir a batalha. Kirk questiona o líder dos organianos, Ayelborne, o que dá o direito de eles interferirem em frotas inteiras. Eles respondem que entendem ser inapropriado interferir em assuntos alheios, mas que a Federação e os Klingons os deixam sem escolha. Kirk e Kor reafirmam o questionamento sobre o que lhe dá o direito de intervir:

KIRK: Even if you have some power that we don't understand, you have no right to dictate to our Federation

KOR: Or our Empire!

$K I R K$ : How to handle their interstellar relations! We have the right.

AYELBORNE: To wage war, Captain? To kill millions of innocent people? To destroy life on a planetary scale? Is that what you're defending?

KIRK: Well, no one wants war. But there are proper channels. People have a right to handle their own affairs. Eventually, we would have

AYELBORNE: Oh, eventually you will have peace, but only after millions of people have died. It is true that in the future, you and the Klingons will become fast friends. You will work together. $^{12}$

As respostas dadas por Ayelborne apresentam vários conceitos do Império como o direito de intervenção e o valor universal da paz. No entanto, a diferença é que a ordem imperial deixa de ser associada com a Enterprise e com as organizações que ela representa, passando a ser vinculada com uma raça alienígena superior na ordem evolutiva. Nessa situação específica, quando outros personagens assumem a representação da ordem imperial, a Federação pode ser associada aos Estados Unidos na Guerra Fria. Dessa forma, a suspensão da história, anteriormente colocada como algo anterior à Enterprise, agora é deslocada para o seu futuro. A afirmação final de Ayelborne sobre o fato de, no porvir, a Federação se unir aos Klingons, demonstra tal questão. $\mathrm{Na}$ ordem Imperial totalizante, antagonistas transformam-se em futuros integrantes da paz.

\footnotetext{
${ }^{12}$ Nossa tradução:

KIRK: Mesmo que você tivesse um poder que nós não entendemos, você não tem o direito de ditar à nossa federação

KOR: Ou nosso Império!

KIRK: Como lidar com nossas relações interestrelares! Nós temos o direito.

AYELBORNE: De fazer guerra, capitão? De matar milhões de pessoas inocentes? De destruir a vida numa escala planetária? É isso que você defende?

KIRK: Bem, ninguém quer guerra, Mas há outros meios. As pessoas têm o direito de cuidar da própria vida. Um dia, talvez...

AYELBORNE: Talvez um dia tenham paz, mas apenas depois que milhões de pessoas terão morrido. É verdade que no futuro vocês e os Klingons se tornarão amigos. Vocês irão trabalhar juntos.
} 
Star Trek, ao deslocar a Federação entre o ente que intervém ou o que sofre intervenção, transforma sua proposta política em valores e funcionamentos universais sem precisar vincular ao longo de toda série tais características a algum personagem ou instituição específica. Por isso, não é possível fazer uma afirmação geral de quem as instituições do seriado representam. Antes de se perguntar a que organismos da política internacional o seriado associa os seus personagens e instituições, é necessário compreender que regras do jogo o seriado propõe como legítimas, em outras palavras, que partilha do sensível (RANCIÈRE, 2005) para as questões mundiais o seriado apresenta. Em nossa análise, entendemos que são as regras do Império, a resposta criada para os anseios da Multidão em terminar com as lutas entre Estados-nação.

Assim, podemos compreender que a contradição apontada por Worland não existe. O seriado defende uma espécie de união pacífica a exemplo ordem imperial. Nas ocasiões em que os personagens principais deixam de se adequar a essa ordem e passam a ser possivelmente associados a uma prática americana imperialista, eles são corrigidos pelos valores imperiais.

\section{REFERÊNCIAS}

BENJAMIN, Walter. Mágia e Técnica, Arte e Política: Ensaios sobre literatura e história da cultura. São Paulo: Brasiliense, 1987.

ESPINOSA, Baruch de. Tratado Político. Coleção os pensadores. São Paulo: Abril. 1983.

HARDT, Michael; NEGRI, Antonio. Império. Rio de Janeiro: Record, 2000.

Multidão: Guerra e democracia na era do Império. Rio de Janeiro: Record, 2014.

JORNADA nas Estrelas. Criação: Gene Roddenberry. CBS, 2013. 23 DVDS.

RANCIÈRE, Jacques. A Partilha do Sensível: estética e política. São Paulo: Ed. 34, 2005.

RODDENBERRY, Gene. Star Trek Writers/Directors Guide. Paramount TV Production, 1967.

SLOTKIN, Richard. Gunfighier Nation: the Myth of the Frontier in Twentieth-Century America. Oklahoma: University of Oklahoma Press, 1998.

VIRNO, Paolo. Gramática da Multidão. Roma: DeriveApprodi, 2002.

WORTLAND, Rick. Captain Kirk: Cold Warrior. Journal of Popular Film and Television, 16 (Fall 1988), 109-117.

Recebido em 25/03/2015. Aprovado em 25/05/2015.

Title: Romulans and Klingons in Star Trek: Antagonists Cold War or prospective members of the pacific order?

Abstract: Article proposes the study of Star Trek: the original series, in particular the relationship of Enterprise with its Romulans and Klingons enemies on first season. The show suggests the defense of values and a way of operating that are consistent with the operation of the imperial order that arose in the context of production of the series. In addition, it is also possible to verify the presence of the crowd desires since the imperial order can be partially understood as a response to their wishes transformers. The concepts of "Empire" and "Multitude" rely on the thought of Antonio Negri and Michael Hardt.

Keywords: Empire. Star Trek. Crowd. Series. 